\title{
(Des)institucionalización, políticas y movimiento feminista transnacional. \\ Una compleja cuestión a la luz de las luchas del presente
}

(De)institutionalization, Politics and Transnational

Feminist Movement. A Complex Question in the Light of the Struggles of the Present

María José Guerra Palmero

Universidad de La Laguna mjguerrapalmero@gmail.com

DOI: http://doi.org/10.15366/bp2019.20.014

Bajo Palabra. II Época. No20. Pgs: 245-262 
Este trabajo se inserta en el proyecto "Justicia, ciudadanía y vulnerabilidad.

Narrativas de la precariedad y enfoques interseccionales" (FFI2015- 63985-C2-R-1)

financiado por el Gobierno de España.

\section{नiverones}

\section{Resumen}

El abordar los procesos de institucionalización y desinstitucionalización motivados por el movimiento feminista es una tarea ingente, pero la confección y devenir de su agenda, en torno al combate contra la violencia de género y la lucha por la igualdad, nos permite atisbar sus objetivos políticos de los últimos treinta años. Situada en el preocupante presente político de ascenso de la ultraderecha, presento la paradoja de un movimiento que nunca ha mostrado mayor pujanza, pero que lo hace en el seno de una constelación política y económica extremadamente hostil. De un lado, el feminismo se ha desarrollado viralmente en un plano horizontal en el que la organización ha sido alérgica a las jerarquías. De otro, ligado a la institucionalización de las políticas de igualdad ha logrado avances, pero también ha cosechado ambivalencias y rechazos. Avanzar en la caracterización del feminismo transnacional y sus agendas desde los años noventa es una tarea de investigación en marcha que no puede dejar de lado la necesidad de articular una respuesta política a la reacción antifeminista en curso.

Palabras Clave: desinstitucionalización, feminismo transnacional, agenda política, políticas de igualdad.

\section{Abstract}

Approaching the processes of institutionalization and deinstitutionalization motivated by the feminist movement is an enormous task, but the construction and progression of its agenda, around the fight against gender violence and the struggle for equality, allows us to glimpse its political objectives of the last thirty years. Situated in the worrying political present of the rise of the ultra-right, I present the paradox of a movement that has never shown greater strength, but that does so within an extremely hostile political and economic constellation. On the one hand, feminism has developed virally on a horizontal plane in which the organization has been allergic to hierarchies. On the other hand, linked to the institutionalization of equality policies, it has made progress, but it has also harvested ambivalences and rejections. Advancing the characterization of transnational feminism and its agendas since the 1990s is an ongoing research task that cannot ignore the need to articulate a political response to the ongoing anti-feminist reaction.

Keywords: deinstitutionalization, transnational feminism, political agenda, equality policies. 
$\mathrm{P}$ ara cualquiera que esté familiarizado con los debates de finales del siglo XX del movimiento feminista en América Latina la confrontación entre un feminismo llamado institucional, que opta por trasladar a las estructuras estatales y supranacionales avances legislativos y pugna por la creación de nuevas instituciones que tengan por objeto la políticas de igualdad, y un feminismo autónomo, que opta por dar protagonismo a la pujanza del movimiento popular y su capacidad de innovación social, no le resultará nueva. Estos términos han sido orillados, aunque no superados, en la explosión interseccional de los feminismos políticos e impugnados por los avatares de unos Estados que han vivido fuertes conmociones al hilo tanto de la globalización como de procesos de cambio institucional, en algunos países también constitucional, que ahora parecen cancelarse y se vuelven claramente regresivos. El contexto de una crisis financiera y económica global ha sido el caldo de cultivo de la instrumentalización política del malestar en contra de los movimientos igualitaristas y a favor del cierre nacionalista e identitario.

Cuando reviso este texto, las elecciones en Brasil están en su punto álgido y nos enfrentan a lo que se puede caracterizar, siguiendo la reflexión de Rita Segato, en una suerte de venganza de los patriarcas y triunfo del supremacismo machista y racista al margen de todo complejo ${ }^{1}$. En lo que sigue, presentaré una cartografía incompleta y tentativa de la compleja cuestión de la (des)institucionalización en el feminismo poniendo el foco en su agenda política. Tal agenda, o agendas, porque los contextos locales, nacionales y regionales, las determinan, es un elemento que sirve para obtener cierta claridad sobre las propuestas concretas de un movimiento que, quizás, junto al ecologismo, es alérgico a la jerarquización y a la verticalidad que implica. El tejido organizacional del feminismo es plural, polimorfo y cambiante. Plataformas, redes, ONGs, asociaciones, Foros y otros marcos organizativos le dan forma y, a la vez, mantienen vivos debates virales y tensiones muy potentes. No obstante, y dependiendo de la historia de cada país, los logros institucionales van desde conformar el rostro del Estado, como en los países nórdicos en los que la alianza con la socialdemocracia ha sido muy fuerte hasta el punto de reconfigurar la misma sociedad — allí la igualdad de género es un eje de la vida política一, hasta la irrelevancia absoluta en los países en los que la misma institucionalización

\footnotetext{
${ }^{1}$ Segato, Rita (2014) Las nuevas formas de la guerra y el cuerpo de las mujeres, México, Ed. Pez en el árbol, Segato, R. (2016) La guerra contra las mujeres, Madrid, Traficantes de Sueños.
} 
del modelo democrático sigue siendo una asignatura pendiente. En medio de este extenso espectro, encontramos todo tipo de situaciones en las que las luchas contra la violencia de género, por la igualdad social y los derechos sexuales y reproductivos conforman un núcleo consensuado de prioridades políticas. El impulso que al movimiento feminista transnacional le prestó, en los primeros años noventa del siglo pasado, las cumbres pro derechos humanos - Viena, El Cairo, Copenhague y la confluencia de múltiples instancias feministas en la agenda de Beijing de 1995- se ha ido agotando en paralelo al debilitamiento de la ONU, de la aspiración a una justicia global y del paradigma de los derechos humanos tras la caída de las Torres Gemelas en Nueva York en 2001.

El escenario geopolítico, volcado en las guerras de Oriente Medio y Próximo desde 2003, el eclipse del movimiento de movimientos por la alterglobalización y, finalmente, el vuelco reaccionario que estamos viviendo desde hace varios años Brexit, ascenso de Trump en la mayor potencia mundial y de las derechas xenófobas en Europa y otras latitudes, así como los rearmes fundamentalistas de las religiones mundiales- han ido en paralelo al agotamiento de las promesas de la globalización. El impacto decisivo ha sido el de una crisis económica global que ha depauperado a grandes sectores y remodelado la geopolítica neoliberal para hacerla transitar hacia un escenario de auge de la reacción particularista que identifica "enemigos" exteriores -los migrantes- e interiores - las mujeres o las personas homosexuales, así como minorías étnicas o religiosas- y que en su vuelta al tribalismo preilustrado nos devuelve a la irracionalidad del modus operandi del chivo expiatorio.

Estos acontecimientos y tendencias, enormemente complejas, señalan un escenario en el que el feminismo, en su doble faceta nacional y transnacional, está siendo un actor político de desafío y cuestionamiento de la ultraderecha. En 2018, tanto en España como en otros países - desde EEUU hasta Argentina o Irlanda- hemos vivido un pico histórico de movilizaciones en torno a diversos temas que van desde la defensa de la democracia y los derechos humanos hasta los derechos reproductivos y la lucha contra la precarización laboral en la inédita huelga del $8 \mathrm{M}$ pasado ${ }^{2}$. La paradoja está servida: nunca el feminismo ha mostrado más músculo político, pero tampoco nunca el contexto político, pura reacción autoritaria y rearme patriarcal, ha sido más hostil a sus objetivos finales de erradicación de la violencia contra las mujeres, con especial énfasis en la de tipo reproductivo y sexual, y del logro de una sociedad ajena a las desigualdades y a las discriminaciones.

\footnotetext{
${ }^{2}$ En Espańa se planteó como huelga laboral, estudiantil, de consumo y de cuidados incorporando nuevas lecturas de un viejo instrumento de la lucha de la clase trabajadora que incluye todo el ciclo de la economía reproductiva y no sólo de la productiva. La Economía Feminista da soporte a un activismo cada vez más afinado en sus análisis de los vectores de opresión sexista.
} 
Mi objetivo, en suma, en las páginas que vienen a continuación, es reseñar, más allá de los consensos y disensos respecto a la agenda feminista, el contexto hostil, esto es, la pinza entre neoliberalismo y neoconservadurismo (proto)fascista ${ }^{3}$ que, sin embargo, enfrenta en el feminismo al movimiento social más activado y beligerante en su contra. Más enfrentado al neoconservadurismo que al neoliberalismo, como veremos, pero con voces muy cualificadas que nos prestan análisis certeros y diagnósticos nada desencaminados. Las energías utópicas de los feminismos, a favor de entrar en la verdadera historia humana y abandonar la prehistoria de la subordinación, no parecen consumirse como la de otros movimientos sociales sino, al contrario, radicalizarse y expandirse.

Me voy a permitir aquí, además, el comentario de que los analistas políticos, que ostentan las tribunas en los medios de comunicación y en las universidades, son culpablemente ignorantes de no haber querido estudiar al movimiento político que más impacto ha tenido en desafiar inercias sociales y culturales en el siglo xx y, que, con renovado empuje, prosigue la tarea en el xxi. No olvidemos que hasta prácticamente los años sesenta del siglo pasado la subordinación de las mujeres se consideraba una invariable antropológica, algo consustancial a la especie humana. La resistencia a considerar "político" al feminismo sigue atrincherada en la academia al margen de la excepción de los estudios de género y el recorrido de las bibliografías de los libros de Ciencia Política lo prueba. La ausencia es ya clamorosa.

Voy a repasar, someramente, algunos de los elementos de mi aproximación al asunto en el contexto de una convocatoria centrada en la desinstitucionalización de la política tal y como explican Griselda Gutiérrez y María Navarro, las editoras de este monográfico en su presentación ${ }^{4}$. El feminismo es anómalo, me temo, respecto a esta clave de análisis. Vayamos por partes.

\section{¿Una agenda política es un elemento de institucionalización?}

Es, EFECTIVAMENTE, ANTE TODO, un instrumento para organizar las acciones y señalar las prioridades. En el seno del feminismo ha sido un elemento básico para delimitar los objetivos de la acción política y ella misma, en sus distintas versiones, ha sido objetada por distintos sectores que no veían recogidas en ella sus reivindicaciones. $\mathrm{O}$, incluso, hilando más fino, si las veían no se quedaban satisfechas

\footnotetext{
${ }^{3}$ Los libros consignados en la bibliografía de Enzo Traverso, Rob Riemen, Carolin Ecke y Arlie R. Hochschild me han permitido adentrarme en la intelección de la constelación reaccionaria.

4 Remito a la "Presentación” que Griselda Gutiérrez y María G. Navarro publican en este número monográfico de Bajo Palabra.
} 
con las formulaciones presentadas. Efectivamente, antes he referido una explosión interseccional que ha enfatizado los cruces de los análisis desde la perspectiva de sexo-género con el antirracismo, la clase social, la etnicidad o incluso, la religión, por ejemplo, en el trabajo de las teólogas feministas. No obstante, estudiando la historia del feminismo vemos que la intersección, ya fuera en las alianzas de las sufragistas contra la esclavitud en EEUU o la problematización de la situación de las mujeres proletarias en el feminismo socialista o anarquista, han sido seminales y no algo forzado a priori. No obstante, la impronta de los ańos noventa, la llamada democracia multicultural, propició que el tópico del reconocimiento se uniera a la redistribución y que hubiera una suerte de inflación de temática identitaria sobre todo en países como Estados Unidos, Canadá o el Reino Unido. La politización y el enfoque securitario de las migraciones, producto reactivo de la globalización económica y mediática, ha alentado un giro reaccionario a este respecto.

Podemos atisbar, en suma, un juego de hegemonías y contra-hegemonías que ha sido interno al complejo y plural movimiento feminista y puede interpretarse desde la óptica de una dinámica interseccional, que tiene sus orígenes en el feminismo afroamericano y chicano y, que, ahora, se expande, por ejemplo, en las críticas desde las emergencias políticas indígenas. El pegamento de la sororidad y las luchas comunes como mujeres son las tendencias centrípetas y las centrífugas remiten a las desigualdades de clase, raza-etnicidad o a las diversidades sexo-genéricas e, incluso, a las diferencias generacionales. En estas dinámicas de solidaridad y/o confrontación se alterna la lucha contra el patriarcado y sus lacras, con la disputa por la hegemonía ahora dirigida contra el constructo "feminismo blanco occidental". Algunas versiones contra-hegemónicas, por otra parte, parecen preferir matar a la "madre feminista" -lo expreso provocativamente- que confrontar al patriarca dentro de la propia cultura o grupo por considerarlo, también, oprimido por la constelación imperialista o colonial. El juego de alianzas y contestaciones, por otra parte, es dinámico y no soporta una foto fija. No obstante, podemos determinar cuatro grandes bloques de consenso en la agenda feminista en todos sus niveles y localizaciones, aunque los contextos determinen las priorizaciones y los énfasis. El potencial utópico de la agenda feminista queda, asimismo, probado en estos cuatro grandes ámbitos. Cada uno de ellos genera a su vez, consensos y disensos. Paso a referirlos.

\section{La utopía de una vida libre de violencia}

LA DENUNCIA DE LOS FEMINICIDIOS y de la violencia de género es la reivindicación más urgente. La afirmación de que si no cesa la violencia contra las mujeres la 
paz es imposible -a cargo de Rita Segato- es una de sus últimas formulaciones. Esta reconexión del feminismo y el pacifismo revela su largo alcance y necesita de una inversión potente de recursos políticos. Exige la visibilización de la genealogía feminista de organizaciones como WILPF (Liga Internacional de las Mujeres por la Paz y la Libertad), que ya se opuso a las guerras mundiales en el siglo xx y que apoya el protagonismo de las mujeres en los conflictos y postconflictos como "constructoras de paz", pero, también, la oposición militante a la "cultura de la violación" y a un patriarcado violento que se conjuga hoy con un capitalismo salvaje que explota, normalizando las violencias estructurales y simbólicas, los cuerpos de las mujeres y que se encuentra en plena escalada bélica amenazando a la humanidad y a la vida sobre la tierra. 2018, en torno a consignas como \#Metoo, ha traído a la palestra la omnipresencia de la violencia sexual y de todo su amplio espectro - desde el acoso sexual en el trabajo hasta la violación como arma de guerra- Desmantelar el carácter violento tanto de la construcción de las masculinidades como de las instituciones fuertemente patriarcales ligadas al negocio de la guerra y de la creación de inseguridad humana es urgente si apostamos por la supervivencia y por la justicia.

\section{La libertad reproductiva}

LA LUCHA POR LOS DERECHOS SEXUALES y reproductivos es y será uno de los grandes caballos de batalla del feminismo de este siglo Xxi. Está formulado desde los orígenes sufragistas, socialistas y anarquistas y sigue siendo clave hoy cuando el derecho al aborto retrocede en varias partes del mundo y en algunas nunca se ha consolidado. Incluso en países donde se garantiza legalmente las dificultades para acceder al aborto son crecientes. Uno de los rasgos de la ultraderecha triunfante es el objetivo de hacer retroceder todo avance en este campo. De hecho, con el polémico nombramiento del último juez de la Corte Suprema estadounidense, Kavanaugh, que consolida una mayoría conservadora, podríamos asistir a la revocación en ese país de la sentencia que dio cobertura al aborto legal, Roe vs. Wade, en los primeros ańos setenta. Las batallas en Argentina, Irlanda o Polonia, así como el Tren de la Libertad (movimiento feminista español que paró el intento de una regresión en los derechos reproductivos). La maternidad forzada y forzosa es una de las consignas más potentes de la emergencia ultraderechista en gran parte del mundo. Las cifras globales sobre muertes por abortos clandestinos y la represión y el encarcelamiento que sufren las mujeres y el personal sanitario que las auxilia siguen siendo estremecedoras. 


\section{El diseño de una sociedad igualitaria}

La igualdad de derechos es la exigencia fundacional del feminismo ilustrado (De Gouges, Wollstonscraft) y del sufragismo, pero la demanda de justicia social hace que el feminismo socialista y anarquista lo hayan dotado, históricamente, de un alcance mayor. El feminismo es alérgico a las desigualdades. Es un igualitarismo radical. No es posible, por tanto, un feminismo de derechas, a pesar de las usurpaciones retóricas de algunas líderes que anteponen su clase social y la defensa de intereses nacionalistas, y o financieros globales, por encima de un igualitarismo radical. El feminismo no admite la explotación ni las viejas o nuevas esclavitudes (Sassen). Es, desde sus orígenes, un movimiento de liberación y emancipación absolutamente incompatible con las visiones de la derecha, sea esta neoliberal o neofascista. Las políticas de igualdad han sido el instrumento institucionalizador - desde organismos de igualdad hasta la enunciación de la transversalidad- de este impulso emancipador. El desfondamiento de las políticas sociales deja, en la mayoría de las ocasiones, a las políticas de igualdad sin sustento. Incluso las convierte en mera retórica vacía. He analizado este asunto para la cuestión de las políticas de igualdad en el contexto meritocrático de las universidades y en paralelo a la institucionalización de los estudios de las mujeres, feministas o de género.

\section{La universalización del cuidado como corresponsabilidad}

Un PROGRAMA a DisCUTIR ES El DE DESNATURALIZAR - no nos tiene que tocar en exclusiva a las mujeres- desprivatizar -considerarlo una responsabilidad pública- y desmercantilizar el cuidado -programa que escuché plantear a la feminista argentina Diana Maffía-. Este último punto supone subvertir toda la economía para ponerla al servicio de la vida y no de los mercados. Da pie a las alternativas de la Economía Feminista en la dirección de una Economía Social y Solidaria. La condición antropológica y ontológica de una vulnerabilidad constitutiva de la especie humana y del planeta exige tal universalización del cuidado y su impacto en las políticas públicas. Es un elemento de clara confluencia ecofeminista, pero también alberga en su seno debates encendidos sobre el significado de la maternidad y las mismas prácticas de cuidado.

¿Qué sostiene todo el impulso político ligado a las reivindicaciones de la agenda feminista? Como ya avanzábamos, unas estructuras muy diversas que van desde lobbies, en los ambientes políticos supranacionales, hasta las organizaciones que cuentan con la espontaneidad como un elemento clave de movilización. La hiperconectividad y las redes sociales han fluidificado los intercambios, pero también están generando polari- 
zaciones debido a las determinaciones del mismo medio tecnológico y a la arquitectura variable de sus algoritmos. El ciberfeminismo ha sido fundamental para la incorporación de las generaciones de millenials y postmillenials al movimiento.

\section{¿Existe aún un feminismo transnacional? ¿Cómo objetivarlo?}

Al hablar De FEMINISMo transNaCional -en los primeros tiempos, en los noventa del siglo pasado, se habló de feminismo global-, se invocan varios elementos también sujetos a contestación:

- Una tradición internacionalista que puede ser rastreada desde el sufragismo al feminismo socialista o al feminismo pacifista - de WILPF a Greenham Common-. Las defensas particularistas y nacionalistas son una contradicción in terminis con un feminismo fundamentado en la igualdad de derechos como evidencian sus orígenes ilustrados.

- Una proliferación de redes, asociaciones y ONGs transnacionales con objetivos feministas que fomentan la interacción entre las agendas locales o nacionales y las agendas transnacionales. Por poner un ejemplo latinoamericano, CLADEM (Comité de América Latina y El Caribe para la Defensa de los Derechos de la Mujer) en América Latina o WEDO (Women Environment and Development Organizations) en relación con el desarrollo y el medio ambiente. La lista sería interminable. Es necesario decir que algunas ONGs han sido cooptadas por fundaciones y líderes globalistas como Soros o como la Fundación Ford a través de la financiación, que pretenden imponer una agenda globalista y pro-negocios fundamentalmente. El tercer sector, y no sólo el feminista, está siendo colonizado por el llamado filántropocapitalismo, pero muchas redes y organizaciones mantienen su independencia.

- Una consolidación, en torno a los lenguajes de los derechos humanos, que se habilita en los primeros años de los noventa del siglo pasado al hilo de las sucesivas Conferencias ya aludidas de la ONU -Viena, contra la violencia, El Cairo, por los derechos reproductivos, y Beijing en donde se nombra la "agenda" del feminismo global. Los años prodigiosos de la movilización feminista a favor de los derechos humanos de las mujeres fueron del 1991 a 1995 y coinciden tanto con la euforia globalista post caída del muro de Berlín, como con los inicios de la activación del olvidado movimiento de 
movimientos por la justicia global. El giro feminista de las grandes ONGs de derechos humanos es otro hecho a consignar.

- La "juridificación" tanto de leyes nacionales, directrices europeas y tratados y convenios internacionales es un indicador de institucionalización derivado del proceso anterior, pero plantea el problema de la eficacia de la ley puesto que las instituciones (por ejemplo, la administración de justicia), siguen siendo reacias a incorporar lo que las juristas feministas denominan como "perspectiva de género”. En España, la traducción institucional y legislativa vendrá en las dos legislaturas de José Luis Rodríguez Zapatero con diversas leyes: -2004, Ley integral contra la Violencia de Género, -2005, matrimonio igualitario, -2006, Ley de Dependencia, -2007, Ley de Igualdad y -2010, Ley de Salud Sexual y Reproductiva que será objeto de un intento de derogación fracasado por parte de la derecha política espańola en 2014. Este despliegue legislativo, que no pudo llegar a consolidar la Ley de Igualdad de Trato, puso a Espańa en primera línea de las políticas de igualdad, pero la falta de voluntad política del gobierno posterior, el de Mariano Rajoy, unido a los efectos de "austericidio", una política económica regresiva, dictados por Europa, han limitado drásticamente el alcance de las acciones y políticas derivadas de estas leyes.

- Otro rasgo a considerar es la interacción entre instancias oficiales - el llamado feminismo institucional- y las mismas organizaciones de la sociedad civil feminista que exigen logros políticos, a la vez que desconfían de las "agendas ocultas" y de las traiciones realizadas por los gobiernos, las instancias privadas de financiación y las instancias intergubernamentales. No tengo espacio aquí para dedicar a las menguantes, debido a la crisis económica, políticas de cooperación y desarrollo, pero este sector ha conjugado intervenciones participativas acertadas, ligadas al empoderamiento de las mujeres locales, con fuertes sesgos neoliberales y neocolonialistas deudores de la falsa promesa de los microcréditos y de la bancarización de las pobres que sigue sin tener repercusión crítica suficiente.

- Por último, quiero abordar un elemento que creo fundamental en el éxito de la huelga del 8M: la "sectorialización" del movimiento feminista. Cada ámbito de actividad, desde el laboral hasta el educativo, sanitario, cultural, etc. ha sido conmocionado por la asociación de mujeres que reconocen el machismo institucional. En las universidades este movimiento ha sido muy claro, pero también en el sector de la cultura -cine, literatura, comic, artes visuales,-. En todos los ámbitos hay esferas formales e informales que se activan en torno a 
conflictos y que confluyen en las movilizaciones transversales contra la violencia sexual, los feminicidios y la sobreexplotación y precariedad laboral. Enumerar estas redes y asociaciones desborda este trabajo, pero la sectorialización es un tipo de institucionalización soft que se revela muy efectiva para visibilizar al movimiento feminista y su transversalidad.

\section{El reciente ciclo de movilizaciones ‘ ¿un feminismo anti(neo)fascista?}

Los CiClOS DE MOVILIZACIÓN TIENEN PICOS NACIONALES, pero fechas como el 8M -el histórico día de la mujer trabajadora- o el $25 \mathrm{~N}$-contra la violencia ejercida sobre las mujeres- son momentos y "rituales" que el activismo modula en función de la agenda y sus prioridades del momento. De hecho, se apunta tentativamente una nueva ola, la cuarta, en torno a la denuncia mundial de la violencia sexual que no desatiende, sin embargo, al resto de los temas candentes en política. La Women's March en Washington, al día siguiente del nombramiento del misógino Trump en Estados Unidos, ha quedado como un hito. En los últimos meses, el \#EleNâo de las feministas brasileñas, movilizadas ya en torno al brutal asesinato de Marielle Franco, contra Bolsonaro sigue en la línea de desafío y confrontación a la emergencia neofascista. En Europa, destacan las marchas de las mujeres polacas contra los retrocesos ligados a las pretensiones de la derecha respecto al aborto. La cercanía de lo que está pasando no nos permite consignar mucha fineza en el análisis, pero sí el que el feminismo se sitúa en primera línea para defender la democracia y los derechos de las mujeres que son abiertamente combatidos por las retóricas neofascistas.

Este 2018 ha sido un año que necesitaremos, en suma, estudiar con calma. Del \#Metoo de las celebrities y su repercusión mediática, amplificada por las redes sociales hasta las movilizaciones contra la impunidad en la que mora la violencia sexual, en España, a cuenta del polémico juicio a La Manada en Pamplona, hasta la ruptura de los tabúes respecto al acoso sexual y sexista en el mundo laboral o en las universidades, quedará como especialmente importante para la historia feminista. No obstante, la lucha contra los feminicidios y la violencia de género del \#Niunamenos permanecerá muy viva. Uno de sus aspectos será la incorporación masiva de una joven generación preocupada no sólo por la violencia y la discriminación, sino, también, por la lucha contra la precariedad laboral y la precarización misma de la vida. Pongo dos ejemplos referidos a España: la denuncia de la sobreexplotación y la precariedad de colectivos especialmente vulnerables como las Kellys -camareras de pisos en los hoteles- o las temporeras migrantes marroquíes de la fresa en Anda- 
lucía, serán focos de atención y solidaridad. El precedente en 2011, en plena crisis de la deuda, del 15M, con sus exigencias de democracia real y justicia social, de un movimiento en el que muchas jóvenes se socializaron políticamente precede al ciclo actual que, creemos arranca en 2014, con un cariz feminista indudable. De hecho, la polémica en el $15 \mathrm{M}$ en torno a la hostilidad hacia el feminismo, esto es, la retirada y posterior vuelta de la pancarta con el lema "La revolución será feminista o no será" fue un precedente muy notable.

De hecho, en España podemos hablar de un ciclo de movilización iniciado en 2014 por el Tren de la Libertad contra el intento de restringir los derechos reproductivos. Aunque las mayores tuvieron la iniciativa, llenas de rabia por ver la perspectiva de retrocesos tras casi cuarenta años de democracia, la participación de jóvenes y de hombres fue una novedad. El 7N de 2016 fue masivo y el 2018 nos ha sobrecogido por la fuerza del movimiento, pero también por la indignación ante la ignorancia de analistas y periodistas. El feminismo español es hoy transversal y está sectorializado, pero, a la vez, ha creado una comunidad de debate e interpretación, está plagado de disensos, pero también de consensos y unidad de acción. Los estudios sobre movimientos sociales tienen un reto para estudiar las dinámicas de desinstitucionalización e institucionalizaciones alternativas. En lo que sigue sólo apuntaré algunos puntos para posteriores consideraciones.

\section{A vueltas con la institucionalización. Ambivalencias y reacciones}

Podemos hablar De ASpectos virtuosos y aspectos viciosos en los procesos de (des)institucionalización en relación con un movimiento horizontal y alérgico a las jerarquías como el feminista. Sintetizo mis apreciaciones al respecto en tres o cuatro puntos, que nos llevan a la cuestión del contexto hostil al que se enfrenta el movimiento. Resulta imposible ser exhaustiva ante tanta complejidad, por lo tanto, sirva sólo de muestra de algunas preocupaciones, continuar las investigaciones y para azuzar el debate. Paso a enumerarlos.

1. Una valoración positiva merece la institucionalización de los estudios de género en las universidades y la mucha más frágil en el resto del sistema educativo, ligada al movimiento coeducativo, puesto que el canon de las diferentes disciplinas se resiste a integrar el protagonismo femenino. Los libros de texto, por ejemplo, son aún inmunes a los cambios y se necesitará todavía de mucha energía para lograr reintegrar a las mujeres a la historia, la literatura, la ciencia o la filosofía. 
2. Los desarrollos legislativos, pueden ser ambivalentes y dependientes de los recursos para su implementación, pero indudablemente confieren legitimidad y prorrogan el protagonismo del debate social. Generan, también, una reacción ligada al rencor y al resentimiento que acompańa a la pérdida de privilegios masculinos, acentuada por la precarización laboral consecuencia del cambio de modelo económico disparado por la crisis de los últimos diez años. Un debate aún incipiente es el de la utilización del derecho penal como instrumento clave en los procesos de erradicación de la violencia. No podemos ser colonizadas por el punitivismo penal, pero tampoco soportar la impunidad para la violencia feminicida y sexual.

3. Más suspicaz soy, como he dejado traslucir antes, con la institucionalización ligada a las dimensiones económicas y que ha generado una suerte de "tecnocracia del género" relacionada con intervenciones de organismos tipo BM, FMI, y similares en las llamadas políticas del desarrollo y la cooperación -aunque esta última esté en horas bajas y constatemos que el tópico de la justicia global ha desaparecido del debate-. Gran parte de la hostilidad en otros continentes con el "feminismo hegemónico" viene de la cooptación por parte del neoliberalismo de las vindicaciones feministas y su remodelación en términos del homo economicus. La promoción de la emprendeduría femenina y de los microcréditos, en el seno de la operación global, de bancarizar a los pobres han sido desempoderadoras y lesivas en su mayor parte, pero el gran aparato de propaganda de las organizaciones económica lo oculta. Esto lo sumo a la crítica de Nancy Fraser a la funesta fusión de feminismo y neoliberalismo, en los EEUU con su obsesión única por romper el techo de cristal y de apostar por el liderazgo empresarial y ejecutivo que renuncia a la crítica a las desigualdades y a la precarización de la vida de las grandes mayorías. En una coyuntura de desmantelamiento de las políticas sociales, las políticas de igualdad se desfondan y/o quedan desvirtuadas.

4. Por último, abordamos lo más preocupante al día de hoy: la reacción neoconservadora a la institucionalización, con tintes de pánico moral en lo relativo a la educación sexual y afectiva en la escuela, que ha utilizado la expresión "ideología de género"- generada en el Vaticano- para estigmatizar los avances feministas. En toda América Latina la reciente ola regresiva la ha utilizado profusamente. Contra Dilma Roussef, en el referéndum colombiano de apoyo al proceso de paz, en el debate en Argentina y Chile sobre el aborto, en las elecciones brasileñas ganadas por Bolsonaro, etc. Las bancadas evangélicas, 
aliadas del catolicismo integrista, son un nuevo fenómeno antifeminista de gran belicosidad.

\section{Paradoja histórica: un movimiento fuerte en un contexto sumamente hostil}

La paradoja QUe estamos DEsvelando es, en conclusión, la de encontrarnos con un movimiento feminista transnacional y sectorializado por ámbitos y temas de trabajo -una de sus fortalezas-, más potente que nunca, y que mejor sabe utilizar la hiperconectividad digital para la movilización por las prioridades de su agenda política. Y todo ello en el contexto más hostil que podíamos imaginar de los últimos treinta años, si contamos como punto de partida del último ciclo histórico la caída del muro de Berlín en 1989 y los primeros años noventa de formulación pujante de la defensa de los derechos humanos de las mujeres, culminando en 1995 en la agenda de Beijing, y sus desarrollos institucionales posteriores. Durante un tramo, hasta 2008, las turbulencias se debieron al avance de la globalización y la hegemonía neoliberal que era ambivalente con las mujeres. De un lado, pugnó por su incorporación como agentes económicos y mano de obra al mercado global -de ahí el fenómeno de la feminización del proletariado internacional en países en desarrollo marcados por la deslocalización de la producción (el fenómeno de las maquilas) o las migraciones y la conformación de cadenas globales de vulnerabilidad ${ }^{5}$ ligadas a nichos laborales feminizados como el cuidado o a la prostitución en los países centrales-, del otro desató una oleada de precarización laboral que afectó fundamentalmente a las clases medias, mujeres y hombres, y que está siendo aprovechada por la retórica particularista y nacionalista de la ultraderecha al culpar a los inmigrantes del malestar económico y social. En los últimos años, los discursos mediáticos y políticos de la ultraderecha han sumado al odio al migrante, intensificado por la inseguridad causada por las guerras de Oriente Próximo y Medio (de Afganistán a Siria, Yemen e incluso Libia) y por el integrismo salafista y wahabí de un país como Arabia Saudí, con el que sin embargo, se siguen haciendo cuantiosos negocios, con los enemigos "interiores" que son las feministas y el colectivo LGTBI por haber desafiado el modelo tradicional de familia. Las vetas xenófobas, aporófobas y racistas se combinan con el pánico moral inducido por la propaganda acerca de la "ideología de género" al tiempo que el autoritarismo y el desfondamiento de la democracia se acentúan con actuaciones que guardan algo más que un aire de familia con el fascismo.

\footnotetext{
${ }^{5}$ A. Jaggar, (2009) "Transnational Cycles of Gendered Vulnerability: A Prologue to a Theory of Global Gender Justice" Philosophical Topics, Vol. 37, No. 2, Global Gender Justice (FALL), pp. 33-52.
} 
El ascenso de la ultraderecha global está capitaneado por EEUU, y, por el Brexit y las ultraderechas nacionalistas en Europa. A Trump, como hemos visto, le hizo frente desde el primer día la Women's March. Y con múltiples dinámicas interseccionales en su seno, y con múltiples polémicas, sigue en la brecha. Analizar las intersecciones del feminismo ante un mandatario misógino e impresentable, con las luchas contra el racismo - Black Lives Matters- o contra la inhumana política migratoria dirigida contra la diáspora mexicana y centroamericana en EEUU son aspectos cruciales en este contexto. La misoginia explícita ha sido contestada con el movimiento \#Metoo con lo que las tensiones reverberan en un panorama político que en lo estatal y mediático es muy hostil al feminismo y al movimiento por la diversidad sexual. En España, como hemos descrito antes ya se dejan notar los efectos de contagio de la ultraderecha globalizada y los partidos de derecha muestran sus cartas volviendo a la hostilidad contra el aborto -en el caso del Partido Popular- y centrados en la promoción de la orientación pro-negocio ligado al cuerpo de las mujeres - un nuevo partido, Ciudadanos centra su política en la defensa de la maternidad de alquiler y la legalización de la prostitución con el fin de emular el sistema alemán y holandés-. Las fuerzas abiertamente fascistas, pero aún minoritarias, se expresan políticamente con discursos misóginos y xenófobos como en el caso de Vox. Las redes sociales y el gusto de los medios de comunicación por el espectáculo que brindan sus líderes, sin duda, les reportará nuevos votantes puesto que ofrecen "soluciones fáciles" a problemas complejos concentrando la rabia social por el malestar en los "enemigos interiores y exteriores". Las complejidades de la cuestión nacionalista en España con el intento secesionista de Cataluña abonan el terreno de su emergencia.

Los conceptos de agencia y empoderamiento, y también el de "resiliencia", han sido colonizados por el neoliberalismo imperante, codificado en imaginarios y eslóganes, frente a la insistencia, de muchas veces las viejas feministas, en las resistentes estructuras de desigualdad y discriminación y la consideración asimismo estructural de la violencia en sus distintas manifestaciones. La oleada neoconservadora y posfascista se propaga apelando a los instintos tribales en el contexto de una reacción contra la globalización que apuesta por el autoritarismo social y no toca el poder de las élites económicas multinacionales. Cual Casandra, y si no hay reacción democrática frente a esta oleada reaccionaria, podremos decir que la conjunción de autoritarismo social, securitización de las políticas y precarización del trabajo y la vida serán el futuro. Desgraciadamente la represión y la violencia se están haciendo fuertes a la vez que desmontan la red de derechos y garantías que habíamos tejido, como feministas y demócratas. Es hora de cerrar filas y luchar contra la marea autoritaria. No queda otra. 


\section{ReferenCias Bibliográficas}

Agra, M. X. "Vulnerabilidad: injusticias y cuidados" en M. L. Boladeras (Ed.) Bioética: justicia y vulnerabilidad. Barcelona, Proteus, 2013, pp. 49-82.

- ¿Olvidar a Clitemnestra? Sobre justicia e igualdad. Santiago de Compostela, USC editora. 2016

Amorós, C. Mujeres e imaginarios de la globalización. Rosario, Argentina, Homo Sapiens. 2008

Amorós, C. y Posada, L. Feminismo y multiculturalismo. Madrid, Instituto de la Mujer. 2007

Benhabib, S. Los derechos de los otros. Extranjeros, residentes y ciudadanos. Barcelona, Gedisa. 2004

- Dignity in Adversity. Human Rights in Troubled Times. New York, Polity Press. 2011

Brown, W. El pueblo sin atributos. La secreta rebelión del neoliberalismo. México: Malpaso. 2015

Emcke, C. Contra el odio. Madrid. Taurues. 2017

Femenias, M.L. El género del multiculturalismo. Bernal. Universidad de Quilmes. 2007

Fraser, N. Fortunes of Feminism. From State-Managed Capitalism to Neoliberal Crisis. London: Verso. 2013

- "Las contradicciones del capital y los cuidados" en New Left Review, 100, septiembre-octubre, (111-132). 2015

- Entrevista recuperada en traducción al español en: http://www.laizquierdadiario.com/Nancy-Fraser-el-feminismo-del-99-y-la-era-Trump.

Hondagneu-Sotelo, P. Domestica: Immigrant Workers Cleaning and Caring in the Shadows of Affluence. California University Press. 2007

Hochschild, A. R. Extraños en su propia tierra. Réquiem por la derecha estadounidense. Madrid. Capitán Swing. 2018

Guerra Palmero, M. J. «Apostar por el feminismo global», en Leviatán. Revista de Hechos e Ideas, núm. 80, 2000, pp. 101-116.

- «Es inevitable el etnocentrismo? Aportaciones feministas a un debate en curso", en Themata, Revista de Filosofía, núm. 39, 2007, pp. 59-65. 
- (2007) «Feminismo transnacional o feminismo global: autoritarismo, poder y pluralidad», en Cuaderno Gris, Revista de Filosofía de la Universidad Autónoma de Madrid, núm. 9, en la edición Democracia, Deliberación y Diferencia, a cargo de Mariano C. Melero, pp. 243-260.

- (2008) «Culturas, género y violencia: prácticas lesivas y derechos de las mujeres», en Isegoría. Revista de Filosofía Moral y Política, núm. 38, pp. 61-76.

- (2010) «Justicia global y analítica de las desigualdades. Pobreza y género», en Isegoría. Revista de Filosofía Moral y Política, núm. 43, pp. 271-282.

- (2014) «Feminismo transnacional, globalización y derechos humanos», en Dilemata. Revista Internacional de Eticas Aplicadas, núm. 15, pp. 161-169.

Gutiérrez, G. Perspectiva de género: cruce de caminos y nuevas claves interpretativas. Ensayos sobre feminismo, política y filosofia. México, M.Á. Porrúa/PUEG/ UNAM, 2002.

JAGGar, A. (2009) "Transnational Cycles of Gendered Vulnerability: A Prologue to a Theory of Global Gender Justice" Philosophical Topics, Vol. 37, No. 2, Global Gender Justice (FALL), pp. 33-52.

Nussbaum, M. Las mujeres y el desarrollo humano. Barcelona. Herder. 1999

Menéndez Espina, S. (2017) «Trabajos femeninos: el valor de los cuidados». Enlace:

http://ctxt.es/es/20170823/Politica/14515/workforall-ctxtprecarizacion-trabajo-domestico-economia-reproductiva.htm

Riemen, R. Para combatir esta era. Consideraciones urgentes sobre fascismo y humanismo. Madrid. Taurus. 2018

Traverso, Enzo Las nuevas caras de la derecha. Madrid, Siglo XXI. 2018

SÁnchez, Cristina, "Sobre el mal y las violaciones masivas contra las mujeres. Aproximaciones desde filósofas contemporáneas", en Quesada, F. Mujeres y guerra. Cuerpos, territorios y anexiones, Biblioteca Nueva, Madrid. 2014

Segato, Rita. Las nuevas formas de la guerra y el cuerpo de las mujeres, México, Ed. Pez en el árbol. 2014

- La guerra contra las mujeres. Madrid: Traficantes de Sueños. 2016

ValCÁrCel, A. Feminismo en un mundo global. Madrid, Cátedra. 2008 
Vega, C. (2017) ¿Quién teme al feminismo? A propósito de la "ideología de género" y otras monstruosidades sexuales en Ecuador y América Latina” Recuperado en: http://www.sinpermiso.info/textos/quien-teme-al-feminismo-a-proposito-de-la-ideologia-de-genero-y-otras-monstruosidades-sexuales-en

Young, I. M. La justicia y la política de la diferencia. Madrid: Cátedra. 2000

Yuval-Davis, N. Gender \& Nation. London, Sage. 1997

DOI: http://doi.org/10.15366/bp2019.20.014

Bajo Palabra. II Época. No20. Pgs: 245-262 